\title{
Current strength, temperature, and bodyscape modulate cleaning services for giant manta rays
}

\author{
Calum Murie $^{1,2,3} \cdot$ Matthew Spencer ${ }^{1} \cdot$ Simon P. Oliver ${ }^{3,4}$ (1)
}

Received: 26 July 2019 / Accepted: 28 February 2020 / Published online: 7 April 2020

(c) The Author(s) 2020

\begin{abstract}
The cleaner-client system among reef teleosts has received considerable attention in both wild and captive environments, but the spatially and taxonomically diverse associations between cleaner fish and elasmobranchs are less understood. Using remote video, we investigated interactions between giant manta rays (Mobula birostris) and cleaner wrasse at a seamount in the Philippines. Cleaning events occurred between 11:00 and 16:00 h on a seasonal basis and were constrained by current strengths and ambient water temperatures. The frequency with which giant manta rays interacted with cleaner fish varied on an individual basis. Blue streaked cleaner wrasse (Labroides dimidiatus) and moon wrasse (Thalassoma lunare) selectively foraged on manta rays' gills and pelvis, with $L$. dimidiatus also demonstrating slight preferences for the pectoral fins. Cleaners' foraging preferences may indicate ectoparasitic infections in specific areas of a manta ray's body. The exclusivity with which giant manta rays visited a particular cleaning station on the seamount may be a response to the quality of services that cleaners provide there. Giant mantas' fidelity to this site may also be attributed to localised concentrations of food that are available nearby. The seamount provides habitat that appears to be important to the life history strategies of the region's giant manta rays.
\end{abstract}

\section{Introduction}

Seamounts are widely regarded as hotspots of biodiversity due to the unique oceanographic conditions that they generate (Morato et al. 2010; Clark et al. 2010) and have been identified as important staging areas for migrant marine megafauna (Worm et al. 2003; Pitcher et al. 2008). While the ecological mechanisms that attract elasmobranchs to seamounts are poorly understood, it has been suggested that

Responsible Editor: J. Carlson.

Reviewed by R. Perryman and J. Stewart.

Simon P. Oliver

s.oliver@chester.ac.uk

1 School of Environmental Sciences, University of Liverpool, Liverpool L69 3GP, UK

2 The Underwater Africa Foundation, Tofo, Inhambane, Mozambique

3 The Department of Biological Sciences, University of Chester, Chester CH1 4BJ, UK

4 The Thresher Shark Research and Conservation Project, Malapascua Island, Cebu, The Philippines they provide refuge, represent social convergence points, act as navigational waypoints, and function as mating, feeding, and nursery grounds for a variety of pelagic species (Worm et al. 2003; Pitcher et al. 2008; Oliver and Bicskos 2014; Wells et al. 2018).

The giant manta ray (Mobula birostris) is one of two recognised manta ray species (Marshall 2009). Reaching $6.70 \mathrm{~m}$ in total (disc) width, the ray is popular among tourists for its size and approachable behaviour. Recognised from fisheries and by-catch to frequent tropical and subtropical offshore waters circumglobally, giant manta rays mature late, have low fecundity, and are classified as Vulnerable to Extinction by the International Union for the Conservation of Nature and Natural Resources' (IUCN) Red List of Species (Marshall et al. 2018). For the past two decades, giant manta rays have been observed by SCUBA divers on Monad Shoal, which is a shallow coastal seamount in the Central Visayas of the Philippines, where they interact with blue streaked cleaner and moon wrasse (Labroides dimidiatus and Thalassoma lunare) (Acebes et al. 2016). Rays, including giant manta rays, are known to host metazoan parasites (Caira and Healy 2004), and it is proposed that they visit a cleaning station at this site to control infection. 
Batoid rays infected with parasites suffer a variety of health consequences. These include skin lesions, necrosis, anaemia, respiratory disease, and chronic bacterial and viral infections that have been reported as lethal in some species (Caira and Healy 2004; Garner 2013). Ectoparasitic infections in captive elasmobranchs cause behavioural modifications such as rubbing against the structures of enclosures and interacting with cleaner fish (Keyes 1982; Reed et al. 2009).

The cleaning system is a classic model of cooperative behaviour among species in which cleaner fish remove ectoparasites and dead or infected tissue from the surface, gills, and sometimes the mouth of client fish (Soares et al. 2011). Interactions with cleaner fish appear to improve the health of teleost clients by reducing their ectoparasite loads, but the benefit of these interactions is less understood amongst elasmobranchs (Grutter 1996; Grutter and Lester 2002; Waldie et al. 2011; Soares et al. 2011; Ros et al. 2011). Clients will often 'pose' near cleaning stations to solicit 'services' from cleaner fish (Bshary and Côté 2008; Oliver 2012). There are approximately 130 species of marine cleaners, with ectoparasitic infection being the most likely proximate cue for clients seeking their services (Keyes 1982; Sikkel et al. 2004; Oliver et al. 2011). The blue streaked cleaner wrasse, Labroides dimidiatus, is an obligate cleaner that preferentially feeds on gnathiid isopod larvae that are known to infect the gills of reef manta rays (Mobula alfredi) (Grutter 1996; Grutter and Bshary 2004; Marshall 2009; O'Shea et al. 2010). L. dimidiatus prefer large clients and interact with manta rays at spatially diverse locations across the globe (Grutter 1996; Grutter et al. 2005; Marshall 2009; Kitchen-Wheeler 2010; Germanov et al. 2019). The moon wrasse, Thalassoma lunare, which is less understood as a cleaner species, also provides cleaning services for manta rays (Kitchen-Wheeler 2010; Barbu et al. 2011; Germanov et al. 2019). Moon wrasse are facultative cleaners wherein only juveniles clean whilst contemporaneously exploiting alternative food sources (Côte 2000).

Cleaners may maximize the profitability of their energy return by selectively foraging on areas of clients where specific types of parasites can be found (Rohde 2005). When investigating how cleaners forage on elasmobranchs, Oliver et al. (2011) showed that L. dimidiatus and T. lunare spent more time inspecting areas of thresher sharks (Alopias pelagicus) that were infected by ectoparasitic digeneans (Paronatrema spp.) compared to areas that are known to harbour other types of parasites (Cadwallader et al. 2015). They concluded that cleaners may optimise their foraging by selecting areas of a client's body that are most likely to produce the highest energy reward per unit effort (Rohde 2005; Oliver et al. 2011). A cleaner's foraging behaviour is, therefore, likely to be driven by the quality of the food patch in relation to the ease with which food may be obtained there (Oliver et al. 2011). Since specific types of parasites infect specific patches of an elasmobranch's body (Caira and Healy 2004; Rohde 2005), it can be predicted that cleaners will show preferences for foraging in some patches over others.

In this paper we show that giant manta rays ( $M$. birostris) interact with cleaners at a seamount in the Philippines and investigate the cleaner-client association. We quantified behavioural interactions between giant manta rays and cleaner wrasse from remote video observations to address the following hypotheses: (1) the dynamics of the cleaner-manta system are driven by environmental factors; and (2) cleaner wrasse preferentially forage on specific areas of a manta ray's body. The cleaner-manta association is discussed in relation to other known cleaner-client systems in the marine environment.

\section{Method}

\section{Location}

Monad Shoal (N $11^{\circ} 19^{\prime}$ 06.7", E 124 $\left.14^{\circ} 31.9^{\prime \prime}\right)$ is a seamount in the Central Visayan Sea, near Malapascua Island, Cebu, the Philippines (Oliver et al. 2011). The top of the mount (15-25 m) is formed by a shallow plateau of low-profile Acropora that is fringed on all sides by a coral reef which crests and sheers down $250 \mathrm{~m}$ to the valley below. An array of cleaning stations lines the southern face of the mount, one of which (Station A) is frequented by giant manta rays (Oliver et al. 2011).

\section{Sampling}

SCUBA divers initially deployed remote video cameras using protocols described by Oliver et al. (2011) at five cleaning stations (A-E) on Monad Shoal during a pilot study which ascertained that Station A was the only location on the seamount where giant manta rays could be observed interacting with cleaner fish. A total of $1171.45 \mathrm{~h}$ of video observations were subsequently recorded from a fixed point on Station A between April 2011 and June 2013, during three field expeditions spanning 262 days over 20 months. A Sony Handycam ${ }^{\circledR}$ HDR-SR8, housed in an Amphibico Elite housing and fitted with a $120^{\circ}$ wide-angle lens, with focal range locked to $0.3 \mathrm{~m}$, was pre-set to record for 360 continuous minutes for all camera deployments. The camera was retrieved at the end of each deployment period, and the video data downloaded for analysis.

Environmental data including tidal conditions, water temperature, and the in situ current strength were documented for each camera deployment. Temperature was measured in situ to the nearest degree Celsius using the readouts of a dive computer at the time of the camera deployment. Current strength was measured from a submerged windsock that 
was fixed to the substrate in the camera's field of view. Tides were estimated from Admiralty predictions for Bogo Bay, the Philippines (ADMIRALTY EasyTide 2013).

\section{Analysis of video recordings}

Video observations of giant manta rays were analysed in 29.97 frames s $^{-1}$ resolution using Final Cut Pro 7 (Apple Inc. CA). Sequences documenting interactions between manta rays and wrasse were classified as cleaning 'events'. These began when a manta ray entered the camera's field of view and ended after it left and did not return for $\geq 5 \mathrm{~min}$. If an individually identified manta (see section below) returned during this time period it was considered to be a continuation of the cleaning event. Because it was not possible to scale a manta ray from its distance to the camera, size was not considered in the analyses. Sex was determined through the presence or absence of claspers.

\section{Identification of individual manta rays}

We took still images of the video recordings when a manta ray was positioned directly above the camera to capture its ventral surface. We then entered the still images into a photo bank that considered patterning in the manta's ventral markings to identify a new individual, or a match to an individual that had been previously observed at Station A following Marshall et al. (2011) and Town et al. (2013). Due to the camera's field of view, it was not always possible to capture the entire ventral surface for each manta ray so some mantas could not be individually identified.

\section{Cleaning interactions}

To investigate whether cleaners forage selectively on giant manta rays, it was assumed that different areas of a client's bodyscape host different types of parasites (Caira and Healy 2004; Rohde 2005) and that some areas represent higher quality food patches for cleaners than others (Bshary and Grutter 2002; Oliver et al. 2011). Eight food patches were outlined on a sketch of a giant manta ray and categorised as 'gills', 'pelvis', 'dorsal head', 'ventral head', 'pectoral', 'ventral body', 'dorsal body', and tail (Fig. 1). These were then used to document cleaner interactions for each event. The pelvic and tail patches included the cloaca and tail, respectively, the pectoral patch incorporated both pectoral fins, the gill patch included both sets of gill openings, and the head patch consisted of the cephalic lobes, the eyes, and the mouth. The ray's dorsal surface was split into two patches, the boundary of which followed the underside of the ray's superbranchial region (Fig. 1).

Cleaning interactions were characterised by a cleaner's mouth making discernible physical contact with a manta ray and were termed 'bites'. Bite locations were individually mapped onto the sketch according to their associated cleaner species (Labroides dimidiatus or Thalassoma lunare) and treated separately in the analyses. Bites were used as a proxy for parasite removal following Oliver et al. (2011). The number of cleaning inspections may be underestimated because cleaner fish activity behind a manta ray could not be observed on the video recordings.

\section{Statistical analyses}

To investigate variation in the distribution of manta ray visits to the cleaning station, a generalized additive model was fitted with a binomial error distribution. The response variable was manta ray presence, or absence, in any given minute during which the camera was recording. The effects of the explanatory variables day of the year, minutes after high tide, minutes after 05:00 and current strength $\left(\mathrm{m} \mathrm{s}^{-1}\right)$ were modelled by thin-plate cubic splines. Knots were
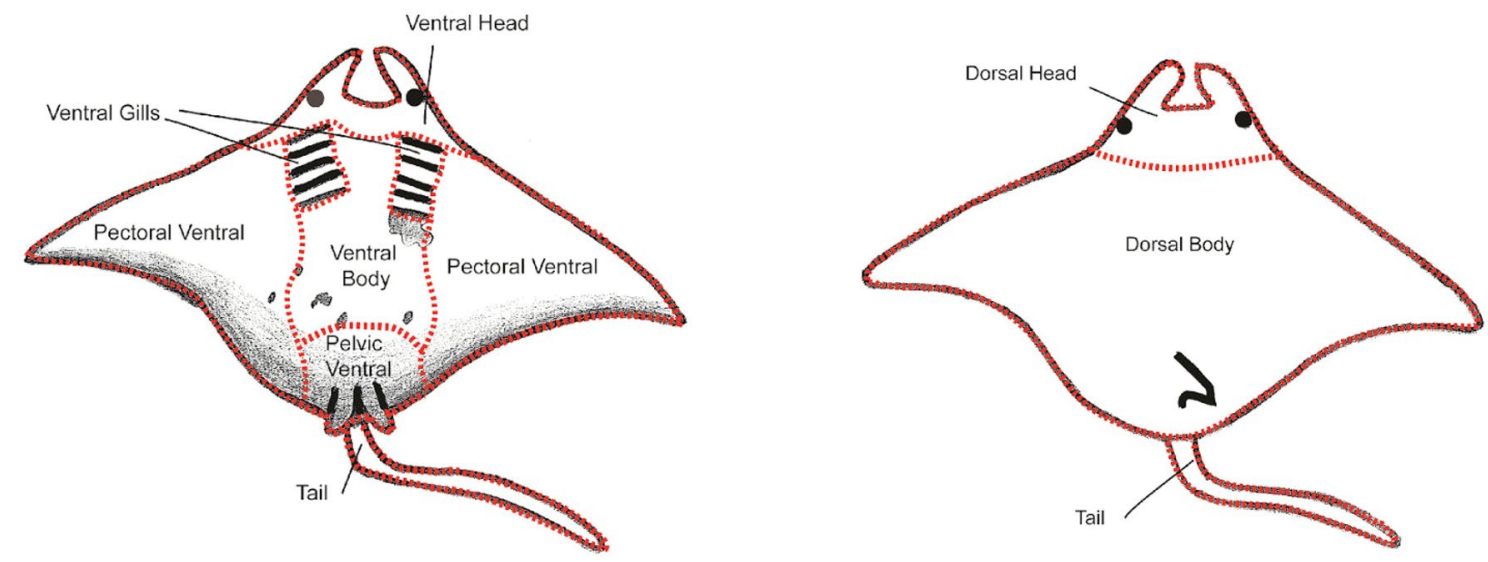

Fig. 1 The food patches onto which locations of cleaning interactions were mapped during the analysis of the video recordings 
conservatively set to three unless we believed there to be more degrees of freedom in the relationship, in which case knots were increased until no further changes were visible when plotting the output (Wood 2017), which occurred in the cases of day of the year $(k=12)$, and minutes after high tide $(k=4)$. Temperature $\left({ }^{\circ} \mathrm{C}\right)$, and minutes observed, were also included as explanatory variables, but with only a linear effect since they took too few distinct values to allow a more complex approach.

To investigate variation in the rate of cleaning interactions, a hierarchical Poisson regression model was fitted. The number of interactions observed in a cleaning event was the response variable, with day of the year, minutes after high tide, temperature $\left({ }^{\circ} \mathrm{C}\right)$, minutes after 05:00, manta ray identity term, and current strength $\left(\mathrm{m} \mathrm{s}^{-1}\right)$ as quantitative explanatory variables. We included an offset term representing the natural log of event time in seconds, under the assumption that the expected number of interactions over the duration of an event was the product of the rate of interactions per second, and the total event time. Event number was included as a normally distributed random intercept term with a mean of zero and an unknown standard deviation, to account for differences between events in the rate of interactions.

To determine how cleaner wrasse foraging differed between patches on a manta ray, another hierarchical Poisson regression model was fitted. The number of cleaning interactions on a given patch of a given manta ray by a given cleaner species was modelled as a random variable with a Poisson distribution. The natural log of the expected number of interactions per unit area (where the unit is the entire surface area of a manta) was modelled as a linear function of patch, cleaner species, and the interaction between patch and cleaner species. To control for differences in patch size, the expected number of interactions per unit area was multiplied by the proportion of body surface area that each patch represents. These area proportions were estimated by counting pixels in each patch on a perpendicular image of a manta ray's dorsal and ventral surfaces in Adobe Photoshop (Adobe Inc., San Jose, California). The effects of event number on the natural log number of inspections were assumed to be drawn from a normal distribution with mean zero and an unknown standard deviation. To examine whether each species of cleaner wrasse preferred specific patches after controlling for patch area, back-transformed patch effects with central $95 \%$ credible intervals were calculated for each cleaner species. These estimates were expressed graphically relative to the preference for the dorsal head patch, with overlapping credible intervals between species indicating that there was not a clear difference in preference.

All analyses were completed in the $\mathrm{R}$ statistical environment (R Core Team 2013), using the rstanarm package (Goodrich et al. 2018), which implements the NUTS algorithm for Bayesian inference (Gelman et al. 2013). Generic weakly informative priors [independent normal $(0,1)]$ (Gelman et al. 2015) were used for all parameters. For each model, four Monte Carlo chains were run for 2500 warmup iterations followed by 2500 sampling iterations. Potential scale reduction factors $(\hat{R})$ were $<1.1$ for all parameters and effective sample sizes $\left(n_{\text {eff }}\right)$ were greater than 2500 , indicating no problems with model convergence. To assess model fits, PSIS-LOO values were computed in the loo package (Vehtari et al. 2017). Pareto $k$ diagnostics and marginal posterior predictive checks were undertaken using the bayesplot package (Gabry et al. 2018) which did not reveal any obvious issues (PSIS $\hat{k}>0.7$ and no evidence of overdispersion). Initial models were simplified through term by term deletions, operating under the assumption that a negative difference in ELPD values of more than two estimated standard deviations indicated a worse model.

\section{Results}

\section{Event frequency}

We identified 15 individual manta rays from 154 cleaning events that were recorded over 60 days during 15 of the study months (April 2011-June 2013). Individual mantas were observed interacting with cleaners for a mean $( \pm$ SE) of $4.4 \pm 0.22$ events (95\% CI 4.18-4.62), and events lasted $5.23 \pm 0.97 \mathrm{~min}$ (95\% CI 5.06-5.56 min).

Nine mantas (M2-M10) were first recorded in 2011, four of which were observed revisiting the site in 2012 (M5, M7, M8, M9). Six mantas (M11-M16) were first observed in 2012, two of which (M12, M13) were observed revisiting the site in 2013. One manta (M9) was observed every year (2011-2013). Across all observations four manta rays were only seen on a single occasion. The remaining eleven $( \pm S E)$ had a return rate of $5.64 \pm 0.27$ (95\% CI 5.10-6.18) across the three observation years.

Comparisons between models of giant manta ray visits showed that the minutes observed, and the minutes after the high tide explanatory variables should be omitted from the final model (Table 1). Manta ray visits to the cleaning station varied throughout the year, occurring most frequently between April and September, with visits rare during March and July (Fig. 2a, Table 2). Visits were most likely to occur during warmer temperatures (Fig. 2b) and in the afternoon (Fig. 2c, Table 2). Visits were also most likely to occur when the current was strong $\left(>1.5 \mathrm{~m} \mathrm{~s}^{-1}\right)$ or weak $\left(\sim 0.2-0.4 \mathrm{~m} \mathrm{~s}^{-1}\right)$, but they were rare when the current was mild $\left(\sim 1 \mathrm{~m} \mathrm{~s}^{-1}\right)$ (Fig. 2d, Table 2). 
Table 1 Comparisons between models of manta ray visits with single-term deletions. "ELPD Difference" refers to the computed differences in the model's ELPD values (each model compared to the model described in row 1), and SE difference is the estimated standard error of the difference

\begin{tabular}{lcl}
\hline & ELPD difference & SE difference \\
\hline $\begin{array}{l}\text { Day of year + minutes after high } \\
\text { tide + minutes after 05:00 + cur- }\end{array}$ & 0 & 0 \\
rent strength & -0.7 & 0.7 \\
Minutes observed & -0.9 & 0.5 \\
Minutes after high tide & -1.1 & 0.2 \\
Temperature & -2.1 & 0.8 \\
Current strength & -8.6 & 4.2 \\
Minutes after 05:00 & -15.3 & 5.5 \\
Day of the year &
\end{tabular}

\section{Cleaning interactions}

There were 32 recorded cleaning events by 11 identifiable mantas for which all data was available. These events lasted between 41 and $2976 \mathrm{~s}$ (mean $1087 \mathrm{~s}$ ) and involved between 1 and 22 discernible cleaning interactions (mean 4.91). Comparisons between single-term deletions of the model for cleaning interactions indicated that all of the explanatory variables should remain in the final model (Table 3 ).

The rate of interactions varied between individual manta rays (Fig. 3b; Table 4), with some (for example M8) receiving much more attention from cleaners than others. The current strength was found to constrain the number of interactions a manta ray received (Fig. 3d), and higher water temperatures had a weakly positive effect (Fig. 3e, Table 4). The minute after 05:00 had a weak negative effect (Fig. 3a), and the day of the year had a weakly positive effect (Fig. 3f; Table 4).

\section{Patch preference}

Single-term deletions of the model for patch preferences by cleaner species indicated that the interaction between the patch and species should be omitted from the final fitted model (Table 5).
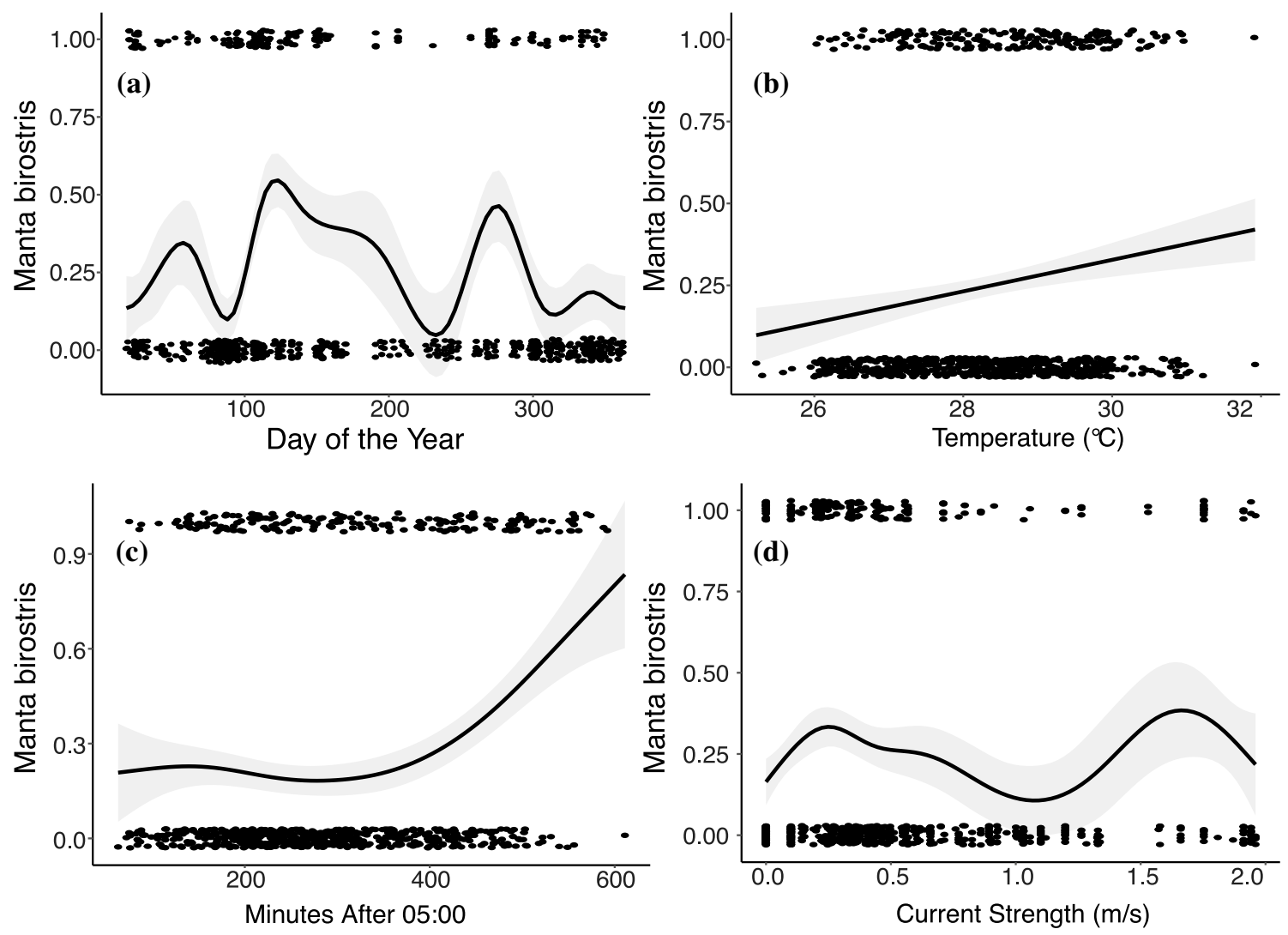

Fig. 2 Manta ray visits to Monad Shoal, and general additive model fits for each of the explanatory variables. a Day of the year. b Time observed. c Current strength $\left(\mathrm{m} \mathrm{s}^{-1}\right)$. d Minutes after high tide. e Minutes after 05:00. Dots represent the presence and absence of giant

manta rays with predicted probabilities on the $y$ axis. Lines represent posterior means and shading around the lines indicates $95 \%$ credible bands 
Table 2 The posterior mean, the 0.025- and 0.975-quantiles of the posterior distribution, and the median absolute deviation (a robust estimate of posterior standard deviation) for each explanatory term included in the final model of giant manta ray visits to station A

\begin{tabular}{lrlrl}
\hline & Mean & MAD Std. Dev & \multicolumn{1}{l}{$2.5 \%$} & $97.5 \%$ \\
\hline Intercept & -1.3 & 0.1 & -1.9799 & 0.2080 \\
Day of the year & 0.6 & 0.3 & 0.1334 & 1.2032 \\
Temperature & 0.8 & 0.5 & 0.0144 & 2.8502 \\
Minutes after 05:00 & 1.4 & 0.9 & 0.1395 & 3.5881 \\
Current strength & 1.1 & 1.3 & 0.0189 & 4.6120 \\
\hline
\end{tabular}

After controlling for differences in patch area and comparing each patch to the 'dorsal head', cleaners showed preferences for certain patches (Fig. 4, Table 6). Both species targeted the gills, which received the largest absolute number of cleaning interactions, with both cleaner species also showing a preference for the pelvis (Fig. 4; Table 6). The pectoral fins received large absolute numbers of cleaning interactions by L. dimidiatus, which resulted in a slight preference for this patch by this species despite its large value for patch proportion (Fig. 4; Table 6). T. lunare's preference
Table 3 Comparisons between models of cleaning interactions with single-term deletions

\begin{tabular}{lcl}
\hline & ELPD difference & SE difference \\
\hline Day of the year + minutes after high tide + minutes after & 0 & 0 \\
05:00 + temperature + current strength & & \\
Minutes after high tide & -17.6 & 2.6 \\
Day of the year & -17.7 & 2.6 \\
Temperature & -19.1 & 2.7 \\
Current strength & -19.8 & 2.3 \\
Minutes after 05:00 & -20.3 & 3.2 \\
Manta ray identity term & -22.0 & 2.9 \\
\hline
\end{tabular}

"ELPD Difference" refers to the computed differences in the model's ELPD values (each model compared to the model described in row 1), and SE difference is the estimated standard error of the difference

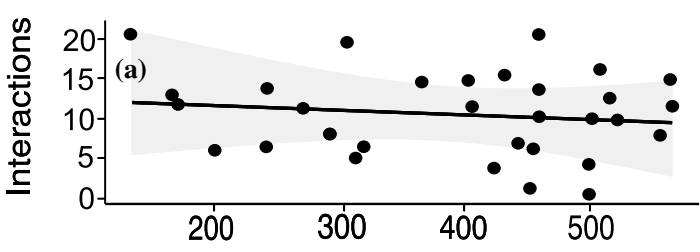

Minutes After 05:00

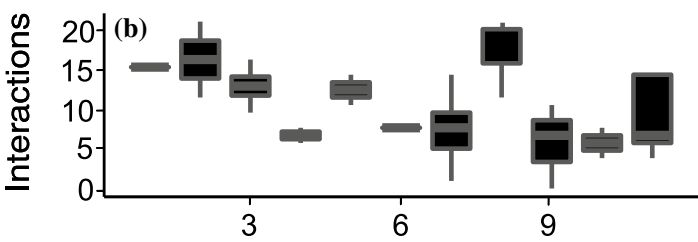

Manta Ray Identification Term

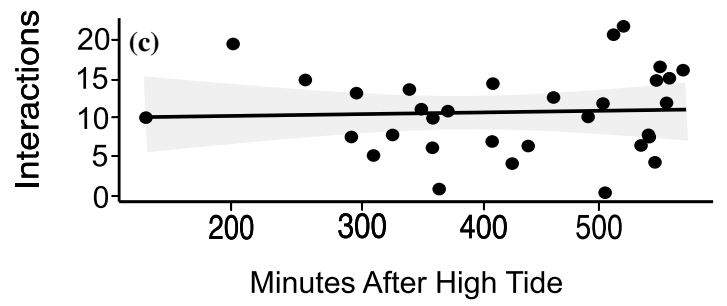

Fig. 3 The rate of cleaning interactions compared between a minutes after 05:00 b Manta ray identification term (boxplots summarize the posterior distributions) $\mathbf{c}$ minutes after high tide d current strength
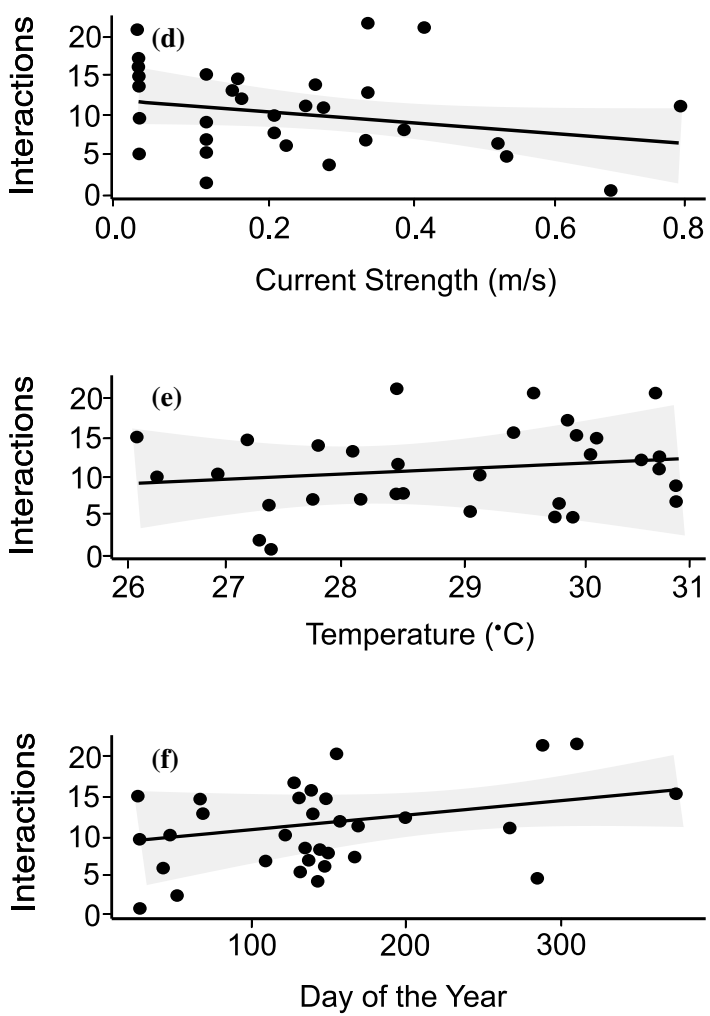

$\left(\mathrm{m} \mathrm{s}^{-1}\right)$ e temperature and $\mathbf{f}$ day of the year. The solid lines represent the posterior mean predictions with shading denoting the $95 \%$ credible bands 
Table 4 The posterior mean, the 0.025- and 0.975-quantiles of the posterior distribution, and the median absolute deviation (a robust estimate of posterior standard deviation) for each explanatory term included in the final interactions model

\begin{tabular}{lrlcl}
\hline & Mean & $\begin{array}{l}\text { MAD Std. } \\
\text { Dev }\end{array}$ & 2.5\% & $97.5 \%$ \\
\hline Intercept & -7.812 & 3.704 & -15.40 & -0.50 \\
Day of the year & 0.003 & 0.002 & 0.001 & 0.007 \\
Minutes after high tide & -0.001 & 0.001 & -0.0028 & 0.0015 \\
Minutes after 05:00 & -0.003 & 0.001 & -0.0059 & 0.0001 \\
Temperature & 0.234 & 0.134 & -0.0276 & 0.5161 \\
Current & -1.904 & 0.986 & -3.9220 & 0.0126 \\
$\begin{array}{l}\text { Manta ray identification } \\
\text { term }\end{array}$ & 0.285 & 0.193 & 0.2562 & 0.3328 \\
\hline
\end{tabular}

Table 5 Comparisons between models of patch preferences by cleaner species with single-term deletions

\begin{tabular}{lcc}
\hline & ELPD difference & SE difference \\
\hline Patch $\times$ species + (1lday) & 0 & 0 \\
Patch + species + (1lday) & -6.9 & 4.4 \\
Patch + (1lday) & -53.7 & 13.0 \\
Species + (1lday) & -455.5 & 74.5 \\
\hline
\end{tabular}

"ELPD Difference" refers to the computed difference in the model's ELPD values (each model compared to the model described in row 1 ), and SE difference is the estimated standard error of the difference

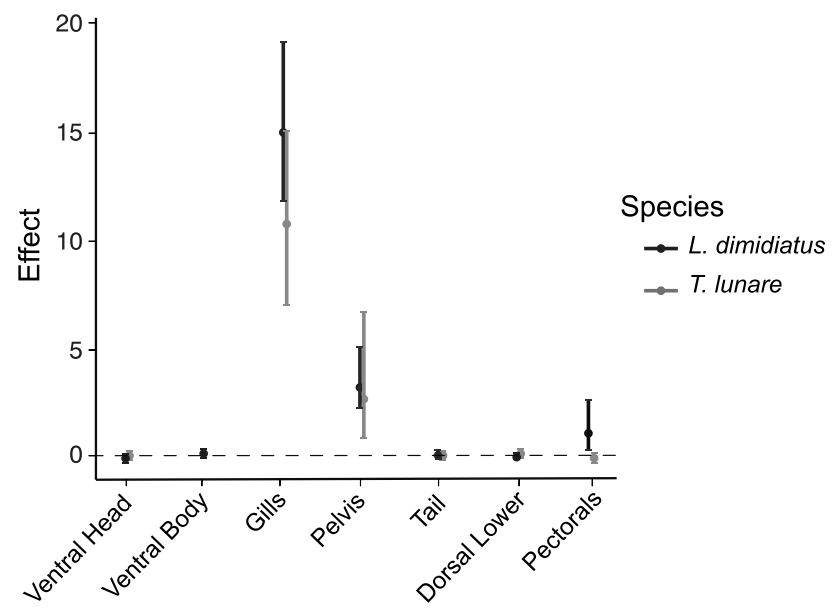

Fig. 4 The effects of patch on the rate of cleaning interactions for $L$. dimidiatus (black), and T. lunare (grey). Effects are expressed relative to the dorsal head patch (dashed line) after controlling for patch area. Dots are posterior means, vertical bars are $95 \%$ credible intervals, and preference is expressed if they do not overlap. The parameter for ventral body, $T$. lunare, has been omitted since it could not be estimated from the data

for the ventral body could not be estimated since no cleaning interactions were recorded in this patch for this species, even though this parameter was structurally identifiable in the analysis (Table 7).
Table 6 The posterior mean, the 0.025- and 0.975-quantiles of the posterior distribution, and the median absolute deviation (a robust estimate of posterior standard deviation) for each explanatory term included in the final patch preferences model

\begin{tabular}{lrlrr}
\hline & Mean & MAD Std. Dev & \multicolumn{1}{l}{$2.5 \%$} & \multicolumn{1}{c}{$97.5 \%$} \\
\hline Intercept & 1.8 & 0.3 & 1.2253 & 2.3584 \\
Patch: ventral body & -1.1 & 0.3 & -1.6809 & -0.5557 \\
Pectorals & -2.2 & 0.4 & -2.8570 & -1.4680 \\
Gills & 0.5 & 0.3 & -0.1224 & 1.0840 \\
Dorsal lower & -2.3 & 0.3 & -2.8868 & -1.6430 \\
Pelvis & 2.0 & 0.3 & 1.4765 & 2.5272 \\
Dorsal head & 0.1 & 0.4 & -0.7912 & 0.7986 \\
Tail & 0.0 & 0.4 & -0.9323 & 0.9139 \\
Thalassoma lunare & -1.1 & 0.1 & -1.3472 & 0.1894 \\
\hline
\end{tabular}

Patch results are expressed in comparison to the "Ventral Head" patch, and results presented for Thalassoma lunare are expressed in comparison to Labroides dimidiatus

Table 7 The patch proportions and absolute number of cleaning interactions recorded in each patch for each cleaner fish species

\begin{tabular}{llcc}
\hline Patch & Patch proportion & $\begin{array}{l}\text { Interactions } \\
\text { from L. dimidi- } \\
\text { atus }\end{array}$ & $\begin{array}{l}\text { Interactions } \\
\text { from T. lunare }\end{array}$ \\
\hline Ventral body & 0.186 & 13 & 0 \\
Pectorals & 0.218 & 51 & 22 \\
Gills & 0.068 & 115 & 89 \\
Ventral head & 0.037 & 4 & 7 \\
Dorsal lower & 0.415 & 12 & 25 \\
Pelvis & 0.012 & 24 & 19 \\
Dorsal head & 0.036 & 5 & 3 \\
Tail & 0.029 & 2 & 3 \\
Total & 1.00 & 226 & 168 \\
\hline
\end{tabular}

\section{Discussion}

While the cleaner-client system amongst reef teleosts has received considerable attention, the spatially and taxonomically diverse associations between cleaners and elasmobranchs are less understood (Couturier et al. 2018; Grutter et al. 2018). This study represents the first attempt to quantify interactions between giant manta rays and cleaner wrasse in the natural environment and supports knowledge of the importance of cleaning stations to marine ecosystems.

\section{Visit frequency}

Our observations of giant manta rays were most likely to occur in the afternoon on a seasonal basis between the 
months of April and September. Giant manta rays' large body size and planktivorous diet make ocean productivity a key factor in determining their movements (Papastamatiou et al. 2012; Braun et al. 2014; Burgess et al. 2016), and seasonal shifts in food availability encourage them to undertake substantial migrations (Dewar et al. 2008; Papastatamatiou et al. 2012; Burgess et al. 2016). Giant manta rays are known to frequent cleaning stations in Mozambique, Ecuador, and Indonesia during the austral winter (Dewar et al. 2008; Rohner et al. 2013; Burgess et al. 2016), and their seasonal fidelity to these sites has largely been attributed to increases in local productivity (Carleton et al. 2001; Pitcher et al. 2008) that is driven by oceanographic processes, including currents (Dewar et al. 2008; O'Shea et al. 2010; Jaine et al. 2012; Rohner et al. 2013; Burgess et al. 2016). It is possible that giant manta rays have limited movements on a regional scale in our study area and that they are only in the vicinity of Monad Shoal when seasonal oceanographic processes promote shifts in productivity and the consequent availability of food (Stewart et al. 2016). They may partition their time to converge on Station A during the afternoon when food is scarce and/or when hydrodynamic conditions facilitate cleaning (see below) (Johansen et al. 2008; Marshall et al. 2011). Similar temporal trends for giant manta rays visiting cleaning stations have been observed in Indonesia where they are known to move offshore to forage nocturnally in deep waters after they clean (Dewar et al. 2008). Mantas' movements and use of our study area may be part of a strategy that considers both temporal variations in food availability and cleaner services without being mutually exclusive (Burgess et al. 2016; Oliver et al. 2019).

The overall occurrence of giant manta ray cleaning events was strongly influenced by the state of the current on the seamount. Certain hydrodynamic conditions may generate sufficient water flow and lift for giant mantas to 'hover' over specific topographical features (Johansen et al. 2008; Marshall et al. 2011). In Mozambique, reef manta rays are known to clean during moderate strength currents because these conditions are favourable for hovering over cleaning stations (Rohner et al. 2013). Hovering may facilitate giant mantas' interactions with cleaners since cleaning typically occurs near spatially finite structures that are known as 'focal points' (Acebes et al. 2016; Stevens et al. 2018). Hovering is also likely to be an energetically efficient strategy that makes giant manta rays more accessible to cleaners and, therefore, more attractive as clients (Acebes et al. 2016; Fish et al. 2018). However, even though hydrodynamic flow may provide lift and facilitate a giant manta's hovering behaviour over a cleaning station, cleaning events were not observed on Monad Shoal when the current was strong. Cleaners are known to seek refuge and conserve their energy during strong currents, which stalls the provision of cleaning services for their clients (Johansen et al. 2008; Eggertsen et al. 2016). The reduced availability of cleaners may have decreased the likelihood of a giant manta ray visiting the site during these periods in spite of the energetic benefits provided by strong currents (Tebbich et al. 2002; Johansen et al. 2008; Fish et al. 2018).

\section{Cleaning interactions}

Reef teleost clients are known to show preferences for specific services that are offered by specific cleaners at specific stations (Bshary and Grutter 2006; Pinto et al. 2011). A client's fidelity to individual cleaners may be driven by the type and quality of service on offer (parasite removal, wound healing, tactile stimulation), or other clients competing for the same resources (Bshary and Grutter 2006; Bshary et al. 2008; Adam 2010). Many of the individual mantas that we observed on Station A had open wounds from bite marks and dismembered cephalic lobes, presumably from encounters with predators and/or fishing gear (Oliver 2012). Giant manta rays' fidelity to this site may be indicative of a lack of competition from other elasmobranch clients, and/or specialist wound healing and parasite removal services that are on offer at this particular location.

Higher temperatures were found to influence the frequency with which giant manta rays visited Station A and were also associated with an increase in the frequency of their interactions with cleaners. Digenean flatworms (Phylum Platyhelminthes) that are known to infect the cloacas of elasmobranchs on Monad Shoal (Caira and Healy 2004; Oliver et al. 2011; Cadwallader et al. 2015) are typically dioxenous, parasitising two hosts during their life cycle (Mills 1979). During reproduction, oviparous digeneans release their fertilised eggs into the water column where they hatch to produce miracidia. The miracidia swim to find an intermediate mollusc host where they grow through several life stages until they eventually emerge as cercaria larvae (Gibson et al. 2002). Larvae live freely in the water column before they attach to their terminal host, which they locate from host-derived chemical or mechanical cues, or shadows (Whittington et al. 2000). Attachment typically occurs during seasonal epizootic events, which are characterised by $\operatorname{cool}\left(\sim 25^{\circ} \mathrm{C}\right)$ or warm $\left(\sim 32^{\circ} \mathrm{C}\right)$ water conditions (Whitfield et al. 1977) and may coincide with a time when hosts are particularly vulnerable to infection (Möller 1978; Silan et al. 1983; Tubbs et al. 2005; Rückert et al. 2008). We conjecture for further study that the seasonality with which giant manta rays visit Monad Shoal might coincide with ectoparasite attachment events in the area, leading to heightened parasitism and a greater need for interacting with cleaners.

Since cleaner fish tend to modify their foraging patterns in response to variations in the quantity and quality of a food resource, giant manta rays with the highest parasite loads are 
more likely to be attractive clients (Oliver et al. 2011; Pinto et al. 2011). Labroides dimidiatus typically favours larger clients with high ectoparasite infections, and a client's body size has been positively correlated with ectoparasite abundance (Barber et al. 2000; Sikkel et al. 2000; Grutter and Bshary 2003; Caira and Healy 2004). The number of cleaning interactions (per unit time) varied substantially among individual mantas across our observations. Although we were not able to quantify body size, it is possible that larger mantas received more attention from cleaners than smaller ones (Sikkel et al. 2000; Grutter and Bshary 2003; Oliver et al. 2011).

Cleaning interactions were patch-specific, suggesting that the cleaners forage selectively across a giant manta ray's bodyscape. Ectoparasites that attach to elasmobranchs are site specific and typically infect the same sites across different host species (Littlewood et al. 1997; Henderson et al. 2002; Caira and Healy 2004; Dippenaar et al. 2008). Platyhelminthes parasitise most elasmobranchs (Caira and Healy 2004), and Paronatrema spp. found in and around the cloaca of pelagic thresher sharks (Alopias pelagicus) that regularly visit our study site are thought to be the primary driver for cleaners preferentially foraging on their pelvis (Oliver et al. 2011; Cadwallader et al. 2015). Monogenean flatworms are similarly known to infect the cloaca of manta rays in Mozambique (Marshall 2009), and gnathiid isopods, which are a primary food source for the blue streaked cleaner wrasse, infect their buccal cavities (Grutter and Poulin 1998; Marshall 2009). While it was not possible to verify whether manta rays visiting Monad Shoal are infected by gnathiids, digeneans, or monogeneans, our observations suggest that either parasitic abundance is highest in and around the cloaca and gills, or that cleaner fish are selecting parasites, mucus, and/or dead tissue there because they are accessible.

\section{Concluding remarks}

Many large marine organisms visit cleaning stations to have parasites removed and giant manta rays appear to regularly visit cleaning stations on inshore reefs. The rays may visit cleaning stations to benefit from feeding opportunities nearby or they may migrate inshore to clean after they forage in deep-water (Burgess et al. 2016; Stewart et al. 2016). Giant manta rays are thought to have limited regional connectivity and so the low number of absolute visits that we recorded either suggests that the habitat no longer supports their requirements, or that they are in regional decline (Stewart et al. 2016). Cleaning interactions are both spatially and taxonomically diverse and cleaners' selective foraging on giant manta ray clients demonstrates a level of preference for areas of a manta's body where specific types of parasites might be found. Future identification and quantification of parasite loads on giant manta rays would offer further evidence that elasmobranch clients provide high-quality food patches for cleaners at seamounts. Cleaning stations are key points of convergence for giant manta rays and they may only frequent specific cleaning stations so these spatially finite habitats should be carefully managed.

Acknowledgements We are particularly grateful to the Governor of the Province of Cebu, and the Municipal Mayor of DaanBantayan for their support and guidance. We thank the staff and volunteers of the Thresher Shark Research and Conservation Project, Gary Cases, and Divelink Cebu for their field and technical support. We are also grateful to Thomas Grotheus for editorial input.

Author contributions SO conceived and performed the experiments. $\mathrm{CM}$ and MS analysed the data. CM wrote the first draft as part of his undergraduate dissertation. SO, CM and MS wrote the final manuscript. All applicable international, national, and/or institutional guidelines for the care and use of animals were followed.

Funding This work was funded by the Thresher Shark Research and Conservation Project. The funding body did not influence the design of the study and collection, analysis, and interpretation of the data nor the writing of the manuscript.

Data availability The datasets generated and/or analysed during the study are available from the corresponding author on reasonable request.

\section{Compliance with ethical standards}

Conflict of interest The authors declare that they have no conflicts of interests.

Ethical standards The research presented in this paper complies with the guidelines from the directives 2010/63/EU of the European parliament and of the Council of 22nd September 2010 on the protection of animals used for scientific purposes. All of the fieldwork was undertaken with the permission of the Governor of the Province of Cebu and adhered to the Philippine 'Wildlife Resources Conservation and Protection Act'.

Open Access This article is licensed under a Creative Commons Attribution 4.0 International License, which permits use, sharing, adaptation, distribution and reproduction in any medium or format, as long as you give appropriate credit to the original author(s) and the source, provide a link to the Creative Commons licence, and indicate if changes were made. The images or other third party material in this article are included in the article's Creative Commons licence, unless indicated otherwise in a credit line to the material. If material is not included in the article's Creative Commons licence and your intended use is not permitted by statutory regulation or exceeds the permitted use, you will need to obtain permission directly from the copyright holder. To view a copy of this licence, visit http://creativecommons.org/licenses/by/4.0/.

\section{References}

Acebes JM, Barr Y, Pereda JMR, Santos MD (2016) Characteristics of a previously undescribed fishery and habitat for Manta alfredi in the Philippines. Mar Biodiv Rec 9:97 
Adam TC (2010) Competition encourages cooperation: client fish receive higher-quality service when cleaner fish compete. Anim Behav 79:1183-1189

ADMIRALTY EasyTide (2013) EasyTide-on-Line Tidal Predictions from the UKHO (Easytide). www.ukho.gov.uk/easytide/EasyTide/

Barber I, Hoare D, Krause J (2000) Effects of parasites on fish behaviour: a review and evolutionary perspective. Rev Fish Bio Fish 10:131-165

Barbu L, Guinand C, Bergmüller R, Alvarez N, Bshary R (2011) Cleaning wrasse species vary with respect to dependency on the mutualism and behavioural adaptations in interactions. Anim Behav 82(5):1067-1074

Braun CD, Skomal GB, Thorrold SR, Berumen ML (2014) Diving behavior of the reef manta ray links coral reefs with adjacent deep pelagic habitats. PloS 9:e88170

Bshary R, Côté IM (2008) New perspectives on marine cleaning mutualism. In: Magnhagen C, Braithwaite VA, Forsgren E, Kappor BG (eds) Fish behaviour. Science Publishers, Enfield (NH), pp 563-592

Bshary R, Grutter AS (2002) Experimental evidence that partner choice is a driving force in the payoff distribution among cooperators or mutualists: the cleaner fish case. Ecol Lett 5(1):130-136

Bshary R, Grutter AS (2006) Image scoring and cooperation in a cleaner fish mutualism. Nature 441(7096):975

Bshary R, Grutter AS, Willener AS, Leimar O (2008) Pairs of cooperating cleaner fish provide better service quality than singletons. Nature 455(7215):964

Burgess KB, Couturier LI, Marshall AD, Richardson AJ, Weeks SJ, Bennett MB (2016) Manta birostris, predator of the deep? Insight into the diet of the giant manta ray through stable isotope analysis. R Soc Open Sci 3(11):160717

Cadwallader HF, Turner JR, Oliver SP (2015) Cleaner wrasse forage on ectoparasitic digeneans (phylum Platyhelminthes) that infect pelagic thresher sharks (Alopias pelagicus). Mar Biodiv 45:613614. https://doi.org/10.1007/s12526-014-0290-8

Caira JN, Healy CJ (2004) Elasmobranchs as hosts of metazoan parasites. Biology of sharks and their relatives. CRC Press, Boca Raton, pp 523-551

Carleton J, Brinkman R, Doherty PJ (2001) Zooplankton community structure and water flow in the lee of Helix Reef (Great Barrier Reef, Australia). Mar Biol 139:705-717. https://doi.org/10.1007/ s002270100611

Clark MR, Rowden AA, Schlacher T, Williams A, Consalvey M, Stocks KI, Hall-Spencer JM (2010) The ecology of seamounts: structure, function, and human impacts. Ann Rev Mar Sci 2:253-278

Côté IM (2000) Evolution and ecology of cleaning symbioses in the sea. Ocean Mar Biol 38:311-355

Couturier LIE, Newman P, Jaine FRA, Bennett MB, Venables WN, Cagua EF, Richardson AJ (2018) Variation in occupancy and habitat use of Mobula alfredi at a major aggregation site. Mar Ecol Prog Ser 599:125-145

Dewar H, Mous P, Domeier M, Muljadi A, Pet J, Whitty J (2008) Movements and site fidelity of the giant manta ray, Manta birostris, in the Komodo Marine Park. Indonesia Mar Biol 155(2):121

Dippenaar S, Van Tonder R, Wintner S, Zungu P (2008) Spatial distribution of Nemesis lamna Risso 1826 (Copepoda: Siphonostomatoida: Eudadctylinidae) on the gills of white sharks Carcharodon carcharias off KwaZulu-Natal. South Afr J Mar Sci 30(1):143-148

Eggertsen L, Hammar L, Gullström M (2016) Effects of tidal currentinduced flow on reef fish behaviour and function on a subtropical rocky reef. Mar Ecol Prog Ser 559:175-192

Fish FE, Kolpas A, Crossett A, Dudas MA, Moored KW, Bart-Smith $H$ (2018) Kinematics of swimming of the manta ray: threedimensional analysis of open-water maneuverability. J Exp Biol 221(6):jeb-166041
Gabry J, Simpson D, Vehtari A, Betancourt M, Gelman A (2018) Visualization in Bayesian workflow. J R Stat Soc A. arXiv:1709.01449

Garner MM (2013) A retrospective study of disease in elasmobranchs. Vet Pathol 50(3):377-389

Germanov ES, Bejder L, Chabanne DBH, Dharmadi D, Hendrawan IG, Marshall AD, Loneragan NR (2019) Contrasting habitat use and population dynamics of reef manta rays within the Nusa Penida marine protected area. Indonesia Front Mar Sci 6:215

Gelman A, Stern HS, Carlin JB, Dunson DB, Vehtari A, Rubin DB (2013) Bayesian data analysis. Chapman and Hall/CRC, London

Gelman A, Lee D, Guo J (2015) Stan: a probabilistic programming language for Bayesian inference and optimization. J Edu Behav Stats 40(5):530-543

Gibson DI, Jones A, Bray RA (2002) Keys to the trematoda, vol 1. CAB International and the Natural History Museum, London

Goodrich B, Gabry J, Ali I, Brilleman S (2018) rstanarm: Bayesian applied regression modeling via Stan. R package version 2(4)

Grutter A (1996) Parasite removal rates by the cleaner wrasse Labroides dimidiatus. Mar Ecol Prog Ser 130:61-70

Grutter AS, Bshary R (2003) Cleaner wrasse prefer client mucus: support for partner control mechanisms in cleaning interactions. Proc Roy Soc Lond B Bio Sci 270(Suppl 2):S242-S244

Grutter AS, Bshary R (2004) Cleaner fish, Labroides dimidiatus, diet preferences for different types of mucus and parasitic gnathiid isopods. Anim Behav 68(3):583-588

Grutter AS, Poulin R (1998) Intraspecific and interspecific relationships between host size and the abundance of parasitic larval gnathiid isopods on coral reef fishes. Mar Ecol Prog Ser 164:263-271

Grutter AS, Lester RJG (2002) Cleaner fish Labroides dimidiatus reduce temporary parasitic corallanid isopods on the coral reef fish Hemigymnus melapterus. Mar Ecol Prog Ser 234:247-255

Grutter AS, Glover S, Bshary R (2005) Does client size affect cleaner fish choice of client? An empirical test using client fish models. J Fish Biol 66(6):1748-1752

Grutter AS, De Brauwer M, Bshary R, Cheney KL, Cribb TH, Madin EMP, Werminghausen J (2018) Parasite infestation increases on coral reefs without cleaner fish. Cor Reef 37(1):15-24

Henderson A, Flannery K, Dunne J (2002) Parasites of the blue shark (Prionace glauca), in the North-East Atlantic Ocean. J Nat Hist 36:1995-2004

Jaine FR, Couturier LI, Weeks SJ, Townsend KA, Bennett MB, Fiora K, Richardson AJ (2012) When giants turn up: sighting trends, environmental influences and habitat use of the manta ray Manta alfredi at a coral reef. PLoS ONE 7(10):e46170

Johansen JL, Bellwood DR, Fulton CJ (2008) Coral reef fishes exploit flow refuges in high-flow habitats. Mar Ecol Prog Ser 360:219-226

Keyes RS (1982) Sharks: an unusual example of cleaning symbiosis. Copeia 1982(1):225-227

Kitchen-Wheeler AM (2010) Visual identification of individual manta ray (Manta alfredi) in the Maldives Islands. Western Indian Ocean Mar Biol Res 6(4):351-363

Littlewood DTJ, Rohde K, Clough KA (1997) Parasite speciation within or between host species? Phylogenetic evidence from site-specific polystome monogeneans. Int J Parasit 27(11):1289-1297

Marshall AD (2009) Biology and population ecology of Manta birostris in southern Mozambique. PhD Thesis, University of Queensland, School of Biomedical Science

Marshall AD, Dudgeon CL, Bennett MB (2011) Size and structure of a photographically identified population of manta rays Manta alfredi in southern Mozambique. Mar Biol 158(5):1111-1124

Marshall AD, Kashiwagi T, Bennett MB, Deakos M, Stevens G, McGregor F, Clark T, Ishihara H, Sato K (2018) Mobula alfredi (amended version of 2011 assessment). The IUCN Red List of 
Threatened Species 2018:e.T195459A126665723. https://doi. org/10.2305/IUCN.UK.2011-2.RLTS.T195459A126665723.en

Mills CA (1979) Attachment and feeding of the adult ectoparasitic digenean Transversotrema patialense (Soparkar, 1924) on the zebra fish Brachydanio rerio (Hamilton-Buchanan). J Fish Biol 2:443-447

Möller H (1978) The effects of salinity and temperature on the development and survival of fish parasites. J Fish Biol 12:311-323

Morato T, Hoyle SD, Allain V, Nicol SJ (2010) Seamounts are hotspots of pelagic biodiversity in the open ocean. Proc Natl Acad Sci USA 107:9707-9711

Oliver SP (2012) The biology and behaviour of pelagic thresher sharks (Alopias pelagicus) in Philippine waters. Bangor University; $\mathrm{PhD}$

Oliver SP, Bicksos AE (2014) A pelagic thresher shark (Alopias pelagicus) gives birth at a cleaning station in the Philippines. Cor Reef. https://doi.org/10.1007/s00338-01401249-8

Oliver SP, Hussey NE, Turner JR, Beckett AJ (2011) Oceanic sharks clean at coastal seamount. PLoS 6(3):e14755

Oliver SP, Grothues TM, Williams AL, Cerna V, Silvosa M, Cases G, Reed M, Christopher S (2019) Risk and resilience: high stakes for sharks making transjurisdictional movements to use a conservation area. Biol Conserv 230:58-66

O'Shea OR, Kingsford MJ, Seymour J (2010) Tide-related periodicity of manta rays and sharks to cleaning stations on a coral reef. Mar Fresh Res 61(1):65-73

Papastamatiou YP, DeSalles PA, McCauley DJ (2012) Area-restricted searching by manta rays and their response to spatial scale in lagoon habitats. Mar Ecol Prog Ser 456:233-244

Pinto A, Oates J, Grutter A, Bshary R (2011) Cleaner wrasses Labroides dimidiatus are more cooperative in the presence of an audience. Curr Biol 21(13):1140-1144

Pitcher TJ, Morato T, Hart PJ, Clark MR, Haggan N, Santos RS (eds) (2008) Seamounts: ecology, fisheries and conservation. Wiley, New York

R Core Team (2013) R: A language and environment for statistical computing

Reed P, Francis-Floyd R, Klinger R, Petty D (2009) Monogenean parasites of fish. Fish Aquatic Sci Univ Florida UF IFAS Extension FA28 USA $4: 1-4$

Rohde K (ed) (2005) Marine parasitology. Csiro Publishing, Oxford

Rohner CA, Pierce SJ, Marshall AD, Weeks SJ, Bennett MB, Richardson AJ (2013) Trends in sightings and environmental influences on a coastal aggregation of manta rays and whale sharks. Mar Ecol Prog Ser 482:153-168

Ros AF, Lusa J, Meyer M, Soares M, Oliveira RF, Brossard M, Bshary R (2011) Does access to the bluestreak cleaner wrasse Labroides dimidiatus affect indicators of stress and health in resident reef fishes in the Red Sea? Horm Behav 59(1):151-158

Rückert S, Palm HW, Klimpel S (2008) Parasite fauna of seabass (Lates calcarifer) under mariculture conditions in Lampung Bay, Indonesia. J Appl Ichthyol 24:321-327

Sikkel PC, Fuller CA, Hunte W (2000) Habitat/sex differences in time at cleaning stations and ectoparasite loads in a Caribbean reef fish. Mar Ecol Progr Ser 193:191-199
Sikkel PC, Cheney KL, Côté IM (2004) In situ evidence for ectoparasites as a proximate cause of cleaning interactions in reef fish. Anim Behav 68(2):241-247

Silan P, Euzet L, Maillard C (1983) The reproduction of Diplectanum aequans (Monogenea, Monopisthocotylea): new data on the anatomy of the genital complex and its functioning. Bulletin de la Société Française de Parasitologie 1:31-36

Soares MC, Oliveira RF, Ros AF, Grutter AS, Bshary R (2011) Tactile stimulation lowers stress in fish. Nat Comms 2:534

Stevens GM, Hawkins JP, Roberts CM (2018) Courtship and mating behaviour of manta rays Mobula alfredi and M. birostris in the Maldives. J Fish Biol 93(2):344-359

Stewart JD, Beale CS, Fernando D, Sianipar AB, Burton RS, Semmens BX, Aburto-Oropeza O (2016) Spatial ecology and conservation of Manta birostris in the Indo-Pacific. Biol Con 200:178-183

Tebbich S, Bshary R, Grutter A (2002) Cleaner fish Labroides dimidiatus recognise familiar clients. Anim Cog 5(3):139-145

Town C, Marshall A, Sethasathien N (2013) Manta Matcher: automated photographic identification of manta rays using keypoint features. Ecol Evo 3(7):1902-1914

Tubbs LA, Poortenaar CW, Sewell MA, Diggles BK (2005) Effects of temperature on fecundity in vitro, egg hatching and reproductive development of Benedenia seriolae and Zeuxapta seriolae (Monogenea) parasitic on yellowtail kingfish Seriola lalandi. Int J Parasit 35(3):315-327

Vehtari A, Gelman A, Gabry J (2017) Practical Bayesian model evaluation using leave-one-out cross-validation and WAIC. Stat Comp 27(5):1413-1432

Waldie PA, Blomberg SP, Cheney KL, Goldizen AW, Grutter AS (2011) Long-term effects of the cleaner fish Labroides dimidiatus on coral reef fish communities. PLoS ONE 6(6):e21201

Wells RJ, TinHan TC, Dance MA, Drymon JM, Falterman B, Ajemian MJ, McKinney JA (2018) Movement, behavior and habitat use of a marine apex predator, the scalloped hammerhead. Front Mar Sci 5:321

Whitfield PJ, Anderson RM, Bundy DAP (1977) Experimental investigations on the behaviour of the cercariae of an ectoparasitic digenean Transversotrema patialense: general activity patterns. Parasitology 79:9-30

Whittington ID, Cribb BW, Hamwood TE, Halliday JA (2000) Hostspecificity of monogenean (platyhelminth) parasites: a role for anterior adhesive areas? Inter Jour Para 30(3):305-320

Wood SN (2017) Generalized additive models: an introduction with R. CRC press

Worm B, Lotze HK, Myers RA (2003) Predator diversity hotspots in the blue ocean. Proc Nat Acad Sci 100(17):9884-9888

Publisher's Note Springer Nature remains neutral with regard to jurisdictional claims in published maps and institutional affiliations. 